\title{
Editorial
}

\section{COVID-19 and the Governance of International Organizations}

\author{
Open Challenges
}

\author{
Gian Luca Burci \\ Adjunct Professor, Graduate Institute, Geneva, Switzerland \\ Gian-luca.burci@graduateinstitute.ch
}

The pandemic of the CoviD-19 coronavirus that has swept the world since February 2020 has frozen the whole international community in its tracks. The pandemic has led to the cancellation or postponement of events, such as the $32^{\text {nd }}$ Olympic Games, that in the past were only disrupted by the two world wars. Progressive moves towards reopening economic and social life since May are facing the challenge of renewed outbreaks and possibly a sustained second wave of the virus. With an effective vaccine still many months away at best, a return to some kind of pre-CoviD-19 normality is not yet in sight.

The work and governance of international organizations could obviously not escape the disruption wrought by the pandemic. From a political perspective, COVID-19 has spurred nationalistic and unilateral reactions rather than international cooperation and coordination. It has also exasperated existing rivalries and divisions (especially the acrimonious relationship between the United States and China) and created new divides including those between close allies. International organizations have found themselves in the crosshairs of these tensions and have reacted differently. On the one hand they have reflected political divisions, as best symbolized by the paralysis of the Security Council for the whole month of April and its adoption of a resolution on 
Covid-19 and international peace and security only on 1 July. ${ }^{1}$ On the other hand, they have provided opportunities for renewed unity and commitment in the face of a common enemy attacking all countries indiscriminately. The strong resolution adopted by the $73^{\text {rd }}$ World Health Assembly (wHA), ${ }^{2}$ and the leadership shown by wHO's Director-General Tedros throughout the crisis, are examples in this direction.

The impact of an unprecedented and unforeseen crisis on international organizations, and multilateral governance more broadly, can be studied from many perspectives and will require a serious research effort at a later stage. In this editorial, I am going to provide a brief overview of the impact of CoviD-19 on the procedures of the intergovernmental organs of international organizations in the first few months of the COVID-19 pandemic, with particular focus on the United Nations and some specialized agencies. ${ }^{3}$

The closure of the premises of international organizations and the impossibility of holding physical meetings has forced organizations to find alternative mechanisms in a very short time to be able to continue to conduct at least the most essential components of their work. These emergency measures were seen as purely temporary and potentially of short duration, but the persistence of the sanitary situation is extending them indefinitely with unclear consequences for the governance of the organizations concerned.

The adaptation measures have varied depending on the governance structure and the context of each organization. The most radical measures were taken by the ILO, which simply postponed the $109^{\text {th }}$ session of the International Labour Conference to 2021 and cancelled the related meetings of its Governing Body; and by the WTO that postponed its $12^{\text {th }}$ Ministerial Conference to 2021. In the case of the ILO, this was made possible in part by the budgetary cycle of the organization, that could postpone to 2021 the adoption of its biennial budget; still, that decision represents a hiatus of one year in the policy-making work of the ILO. The FAO's biennial Conference is scheduled to meet in 2021, thus no particular measures were required in that connection, while other meetings were postponed to late 2020. Other organizations, for example the WHO and the Interparliamentary Union (IPU), had to organize

1 UN Doc. S/RES/2532 (2020), 1 July 2020.

2 wно Doc. WHA $/ 73 / 1$.

3 An excellent overview of the changes introduced by the principal organs of the United Nations is Giuseppe Nesi, "The United Nations principal political organs and the universal pandemic: How to meet, negotiate and deliberate under 'new, extraordinary and exceptional circumstances'? QIL-Questions of International Law 70 (2020) 5-20, http://www.qil-qdi.org/ the-united-nations-principal-political-organs-and-the-universal-pandemic-how-to-meet -negotiate-and-deliberate-under-new-extraordinary-and-exceptional-circumstances/. 
sessions of their plenary bodies entirely on-line while the UN, with the General Assembly constantly in session and the Security Council constitutionally required to meet at short notice virtually in any circumstance, prioritized written decision-making procedures that enable them to continue to adopt at least urgent resolutions. The UN General Assembly has resumed a few physical meetings as of the end of August while respecting personal distancing requirements, but on-line meetings will remain the norm for the moment. The general debate of the $75^{\text {th }}$ session in September is scheduled to take place in a "hybrid format", whereby a limited number of diplomats from permanent missions will gather in the Assembly hall, while high-level government officials from capitals will deliver video-recorded statements. Regional organizations also had to adapt their procedures and take a policy decision on a politically realistic balance between safety and efficiency. The Permanent Council of the Organization of American States (OAS), for example, decided on 16 April in general terms to continue its work and that of its subsidiary bodies virtually until optimal conditions for physical meetings resume. ${ }^{4}$

The WHO offers an illustrative example of the extent of the adaptations that international organizations had to undertake to continue to conduct their work. The wHA held a two-days abridged virtual session in May to carry out essential governance functions such as the election of members of the Executive Board, and to adopt a resolution on the international response to COVID-19. At the same time, the WHA decided to resume its session in November to discuss the rest of its regular agenda. As of the time of writing this contribution, it is likely that also the resumed session will be held online or in a hybrid format. The Secretariat drafted special procedures ${ }^{5}$ applicable to the $73^{\text {rd }}$ as well as any future virtual session, that were discussed with member states in informal virtual briefings during the preceding months and eventually adopted at the opening of the session. The briefings were mostly conducted with the permanent missions based in Geneva, thus excluding the about twenty states without a mission. The special procedures suspended the application of specific rules of procedure incompatible with the online format of the Assembly, while the remaining rules continued to apply. This careful and conservative carve out of a relatively small number of the regular rules of the Assembly probably helped in reassuring delegates that they were still treading on familiar procedural ground. Holding a virtual plenary session with member states connecting from all over the world required carefully timed staggered meetings that lasted until late at night also to accommodate predictable difficulties

4 OAS Dox. CP/RES. $1150(2280 / 20), 16$ April 2020.

5 wно Doc. A/73/33, 17 May 2020. 
in online connections; in several cases, pre-recorded video statements replaced live ones and will be included in the official records of the Assembly. Most importantly, the need to limit and shorten to the maximum possible extent the work of the Assembly led to limiting speaking rights to member states and other international organizations, while non-governmental organizations and other participants could only post written statements on the WHO's web site. In order to streamline the remaining work, draft resolutions that in the view of the Assembly's President could gather consensus were circulated under a no-objection procedure; in case of any objection, the proposals would be considered at the resumed session. At of the time of writing, four resolutions and eight decisions were adopted through this mechanism that is proving quite effective in reducing the workload of the resumed session. In contrast to this substantial adaptation, the aforementioned resolution of the OAs Permanent Council states explicitly that its Rules of Procedure will continue to govern virtual meeting, including notably quorum and voting processes, and does not introduce extraordinary procedures.

Adapting the procedures and methods of work of the principal organs of the UN, in particular the Security Council, proved delicate and challenging. The special procedures of the Council, the General Assembly and Ecosoc are adopted on a monthly basis and constantly renewed in order to underscore their exceptional nature, rather than having open-ended arrangements to be terminated when normal conditions resume. The principal organs have agreed to a written procedure for the adoption of resolutions, whereby their respective presidents circulate draft texts with a short deadline for voting through a written communication. In the case of the Assembly and Ecosoc, consensus is required for the adoption of resolutions, which are considered as rejected in case of even a single objection. This makes the process more fragile and vulnerable, but at the same time it imposes a significant burden for a state to singlehandedly veto a decision. In the case of the Council, instead, a consensus requirement would have been incompatible with the exercise of veto rights and each member has to indicate how it votes. Even agreeing on the format of the meetings proved difficult for the members of the Council, some of which (including reportedly the Russian Federation and China) initially argued that videoconference proceedings could not be considered "meetings" of the Council under its provisional rules of procedure. ${ }^{6}$ The worsening of the sanitary situation in New York made it impossible to sustain that position and led to the adoption at the end of March of exceptional arrangements for the adoption of

6 Giuseppe Nesi, above n. 3 [15]. 
resolutions, ${ }^{7}$ supplemented later by elaborate and carefully negotiated arrangements on the open or closed status of videoconference meetings, transparency requirements and the participation of non-Council members. ${ }^{8}$ The discomfort of some members with these more informal procedures is shown, for example, in the decision not to publish verbatim records of the videoconferences, thus preempting the establishment of official records of what still remain Security Council meetings.

The adoption of the foregoing arrangements, and comparable ones in other organizations, is limiting and risks distorting the essence of multilateral governance and diplomacy embodied in the work of international organizations; the risk is even more pronounced if the sanitary situation does not improve and those arrangements remain applicable during 2021 or even longer. To give just some examples, the agenda of some organs (for example the Governing Council of the IPU that will hold an extraordinary session in November 2020 in lieu of the IPU Assembly) has to be restricted to essential items and members cannot propose additional items. An online format makes it virtually impossible to engage in the dynamics of multilateral meetings such as negotiating draft resolutions, introducing amendments or additional proposals, raising procedural motions and in general engaging in a parliamentary-style debate besides prepared statements. The no-objection procedure adopted by the General Assembly and Ecosoc, moreover, oversimplifies decision-making and prevents states from expressing dissent or objections without blocking a resolution. This kind of decision-making processes inevitably reduces the space for arriving at a truly agreed decision and places many member states before an uncomfortable "take-it-or-leave-it" situation. This, in turn, may make states reluctant to consider substantive resolutions, whose adoption may set a precedent for future similar decisions, through a no-objection procedure. The space for negotiations in these cases mostly consists of informal consultations conducted before the meetings, which of course raise their own challenges when conducted virtually. The resolution on COVID-19 adopted by the WHA, for example, was introduced by the European Union that led and coordinated various rounds of negotiations. This informal method of multilateral diplomacy may be effective when conducted skillfully and amplifies in any case what already happens in practice, in particular in organizations that hold relatively short intergovernmental meetings during which prolonged negotiations would be difficult. At the same time, virtual multilateral diplomacy either within or outside formal meetings inevitably accentuates the divide between countries

7 UN Doc. S/2020/253, 27 March 2020.

8 UN Doc. S/2020/372, 7 May 2020. 
with unequal technological and connectivity resources. That inequality piles up on top of existing economic and developmental gaps and risks widening even more the power differentials within international bodies.

As noted above in the case of the recent WHA, the diversity of voices in multilateral governance ensured by the participation of non-state actors and other participants in the meetings of governing bodies may have to be curtailed by the need to compress online meeting time and prioritize participation by member states. The lack of a shared physical space, moreover, deprives nongovernmental organizations and other non-state actors from the possibility of lobbying, making contacts and establishing or strengthening networks and alliances, that often constitute the real priority objective of their participation. Non-state actors have used their virtual networks to soften the impact of this development, but this does not really remedy the lack of physical proximity and impoverishes the content and meaning of multilateral governance. This impoverishment of multilateral governance is multiplied by the cancellation of the panoply of important and well-attended side events as well as informal meetings (occasionally between states that could not meet publicly but can do so discreetly behind the scenes) that characterize inter alia the first part of the regular session of the General Assembly.

As noted above, this brief editorial has focused on the intergovernmental machinery of international organizations. Of course, the sanitary emergency caused by CoviD-19 has had an equally dramatic effect on the functioning of secretariats. The closure of premises almost overnight made it necessary to reorganize the work of secretariats almost entirely online, with only essential staff allowed on premises. Even after the initial acute emergency subsided and more staff could return, the need to maintain personal distancing has led to rotational arrangements for staff sharing the same physical space. Needless to say, these unforeseen and unprecedented arrangements have raised major challenges at an individual and organizational level and inevitably affected the implementation of many activities and programs. They also affected negatively outreach and public activities, including notably depriving thousands of students worldwide of the possibility of applying for internships and familiarizing themselves with the work of international organizations.

The measures briefly reviewed in this editorial have proved unavoidable as short-term emergency arrangements to manage the impact of CoviD-19; their negative implications had to be balanced against the imperative of health safety and to reflect travel and other restrictions. However, the persistence of the pandemic and consequential travel and meeting restrictions should lead to a careful consideration of how to ensure public safety while preserving the integrity and fairness of the governance of international organizations for an 
extended period of time. The reduction of membership rights, the narrowing of negotiation spaces, the exclusion of many essential voices from meetings, and the accentuation of economic and technological obstacles and inequalities among member states are not consistent with basic principles of good governance at the multilateral level. 